\title{
LA BIOLOGÍA MOLECULAR EN LA TRAYECTORIA ARTÍSTICA DE SALVADOR DALÍ
}

\author{
DANIEl LóPEZ DEL RINCÓN \\ Universidad de Barcelona \\ dlopezdelrincon@ub.edu
}

\begin{abstract}
La relación de Salvador Dalí con la ciencia es una de las facetas más destacadas de su producción artística, que ha abarcado disciplinas como la física, las matemáticas o la biología. Teniendo en cuenta el interés que Dalí manifestó por otras ciencias, nuestro objetivo es profundizar en la particular relación del pintor con la biología molecular, estableciendo un catálogo de obras que nos permitan identificar su valor en la trayectoria artística del pintor. Se propondrá que lo que se ha denominado como "periodo del ADN" cubriría una cronología más amplia que la que se ha establecido tradicionalmente, debiéndose avanzar hasta el 1957 y prolongar hasta la década de los ochenta del siglo XX, situando a Dalí como el pionero en la incorporación de la biología molecular a la historia del arte.
\end{abstract}

Palabras clave: Salvador Dalí; biología molecular; ADN; bioarte.

\section{MOLECULAR BIOLOGY IN SALVADOR DALI'S ARTISTIC CAREER}

Salvador Dalí's relationship with science is one of the most important aspects of his artistic production, spanning disciplines such as physics, mathematics and biology. Considering his interest in the different sciences, the aim of this paper is to explore the special relationship between the painter and molecular biology, establishing a catalogue of works permitting the identification of its importance within Dalí's career. We will try to demonstrate that the so-called «DNA period» encompasses a broader chronology than the one traditionally proposed, extending it from 1957 until the 1980s. That would place Dalí as the pioneer in the incorporation of molecular biology into art history.

Key words: Salvador Dalí; Molecular biology; DNA; Bioart.

El interés de Salvador Dalí por la biología molecular constituye una de las facetas menos estudiadas de su relación con las ciencias, que ha abarcado otros ámbitos disciplinares como la física o las matemáticas. Las causas de este desinterés pueden ser múltiples aunque nos gustaría señalar, principalmente, dos: en primer lugar, la importancia que otras disciplinas científicas, y muy especialmente la física nuclear, han tenido en el análisis de Dalí y las ciencias y, en segundo lugar, la ausencia de referencias explícitas a la biología molecular en los textos de Salvador Dalí.

Nuestro propósito con este artículo ${ }^{1}$ es recuperar las aportaciones que diversos autores (presentes en la bibliografía y citados puntualmente en las notas al pie) han realizado al respecto, para

\footnotetext{
${ }^{1}$ Esta investigación se ha realizado en el marco del proyecto de investigación Arte y Nuevas Materialidades (MINECO, HAR2014-59261-C2-1-P) y constituye una versión revisada y ampliada (en contenidos e imágenes) del trabajo realizado por el mismo autor en el marco del libro Bioarte. Arte y vida en la era de la biotecnología (López del Rincón, 2015: 53-67).
} 
ampliar el catálogo de obras que se han considerado, hasta el momento, constitutivas de la relación entre Dalí y la biología molecular. No se trata, exclusivamente, de ampliar cuantitativamente este catálogo sino que la toma en consideración de obras nuevas, implica una mayor comprensión de las otras obras tanto individualmente como en su conjunto, así como un notable ensanchamiento de la cronología que cubre el interés daliniano por la biología molecular. Ello lo situaría, como se ha señalado en otro lugar ${ }^{2}$, en el iniciador, junto con Edward E. Steichen, de la historia de relaciones entre arte, biología y biotecnología, que también destacaremos en su momento.

La exposición Dalí. Todas las sugestiones poéticas y todas las posibilidades plásticas (Centre Georges Pompidou, 21 de noviembre de 2012 - 25 de marzo de 2013, París; Museo Nacional Centro de Arte Reina Sofía, 27 de abril - 9 de septiembre de 2013, Madrid), supuso tanto la reunión de un conjunto significativo de obras del artista como una contribución científica al conocimiento del mismo. En este sentido, es destacable que la relación entre Dalí y la biología molecular estaba presente, si bien de una manera testimonial. En el catálogo que recoge las aportaciones de la exposición, las referencias a la biología molecular se reducen a dos documentos, presentes en el apartado "Ciencia, Mística y Teoría". Nos referimos al collage que realizó para la cubierta del catálogo de la exposición Hommage à Crick et Watson (1963) y al dibujo del Discóbolo realizado para el libro de James D. Watson, La doble hélice $e^{3}$ En el texto del catálogo la relación de Dalí con la biología se limita a la mención de la obra Galacidalacidesoxyrribonicleicacid (Hommage à Crick et Watson) (1963), que suele considerarse, por parte de los autores presentes en la bibliografía, como el punto de partida de la relación entre Dalí y la biología molecular.

En términos genéricos, esta relación debe enmarcarse en una reflexión más amplia, como es la de Dalí con las ciencias, que se ha clasificado tradicionalmente en seis épocas, según la propuesta de Joan Senent Josa ${ }^{4}$, que recupera Daniel Giralt-Miracle ${ }^{5}$ : el periodo surrealista (19221939); el periodo nuclear o atómico (1940-1957); el periodo microfísico (1958-1960); el periodo del ADN (1963-1975); el periodo holográfico y estereoscópico (1971-1978) y el periodo de la teoría de las catástrofes (años ochenta). Esta clasificación pone de relieve la gran influencia que tuvieron, a partir de la década de los cuarenta del siglo XX, determinadas disciplinas científicas que abarcan la física, las matemáticas o la biología en la obra del pintor.

Partiendo del marco general de relación de Salvador Dalí con la ciencia, el presente trabajo analiza la particular relación del pintor con la biología molecular, estableciendo un catálogo de obras, que serán analizadas tanto individualmente como en su conjunto, identificando el valor artístico asignado por Dalí a esta disciplina científica. Trataremos de demostrar que el llamado "periodo del ADN" abarcaría una cronología más amplia que la propuesta por los citados Senent Josa, Giralt-Miracle o, más recientemente, Carme Ruiz, que remonta su inicio al $1962^{6}$, considerando que habría que avanzarla hasta el 1957 y prolongarla hasta la década de los ochenta. El avance de la cronología nos permitirá valorar el carácter pionero de la obra de Dalí en la incorporación del interés por la biología molecular al arte del siglo XX, un aspecto relevante teniendo en cuenta dos factores: uno, de carácter científico, ya que el descubrimiento de la estructura helicoidal del ADN se produjo en 1953, solo cuatro años antes de que Dalí lo representará con extrema precisión en su obra, confirmando la atención que prestaba el pintor a las innovaciones científicas; y, dos, de carácter artístico, porque en la actualidad (y especialmente desde la década de los noventa del pasado siglo) un nutrido grupo de artistas están relacionando su trabajo artístico con las innovaciones

\footnotetext{
2 López del Rincón/Cirlot, 2013: 64-65.

${ }^{3}$ Martin, 2013: 474-475

${ }^{4}$ Senent Josa: 1988.

${ }^{5}$ Giralt-Miracle, 2005: 474-475.

${ }^{6}$ Ruiz, 2010: 4-13.
} 
de la biotecnología en lo que se ha denominado genéricamente como "bioarte", un aspecto importante para situar a Dalí como artista pionero en este ámbito.

\section{El descubrimiento de la biología molecular en el siglo XX}

La progresiva importancia que han adquirido los desarrollos tecnológicos asociados a la biología molecular (clonación, transgénicos, ingeniería de tejidos...) han situado, a principios del siglo XXI, la biología en un lugar predominante en el conjunto de las ciencias, lo que ha llevado a autores como Jeremy Rifkin, a anunciar el advenimiento de "el siglo de la biotecnología" . Pero las actuales investigaciones científicas e innovaciones tecnológicas hunden sus raíces en los desarrollos científicos del segundo tercio del siglo XX que es, precisamente, el contexto en el que Salvador Dalí iniciará su interés por la biología molecular.

"There is not consensus of opinion amongst geneticists as to what genes are -whether they are real or purely fictious- because at the level at which genetic experiments lie, it does not make the slightless difference whether the gene is a hypothetical unit, or whether the gene is a material particle" . Con esta frase del mismo año en que le concedieron el Premio Nobel de fisiología y medicina (1933), el embriólogo Thomas Hunt Morgan (1866-1945), expresó el desconocimiento existente entre la comunidad científica con respecto a la verdadera naturaleza del gen. A partir de entonces se desarrollaría un creciente interés por la búsqueda de la naturaleza físico-química del gen, lo que conduciría, en última instancia, al surgimiento de la disciplina de la biología molecular. Sería precisamente un físico, Erwin Schrödinger (1887-1961), Premio Nobel en 1933, el que en 1944 publicaría el texto What is Life? donde retomaba las dudas sobre la definición del gen, preguntándose por el papel que podían desempeñar la física y la química en la comprensión de la vida $^{10}$, lo que puede entenderse como el principio del fin de la genética clásica (o mendeliana), es decir, como el desarrollo de un creciente interés entre la comunidad científica por encontrar la base material de la genética que recibiría, a finales de la década de los treinta el nombre de "biología molecular" por parte de Warren Weaver (1894-1978).

No será hasta el año 1953 cuando los biólogos James D. Watson (1928) y Francis Crick (19162004), ambos Premio Nobel de fisiología y medicina en 1962, publiquen su modelo de estructura molecular del $\mathrm{ADN}^{11}$, con su característica forma de doble hélice. Francis Crick formulará en 1958 lo que se conoce como el "dogma central" de la biología molecular: la información genética fluye desde el ADN a las proteínas por medio del ácido ribonucleico (ARN), por medio de la transcripción del ADN en ARN, y de la traducción del ARN a proteína. También Rosalind Franklin (1920-1958), gracias a sus investigaciones con rayos X pudo demostrar que la estructura del ADN era regular. El modelo molecular descrito por Watson y Crick tuvo escasa repercusión en los años posteriores, incluso en la comunidad científica. Philip R. Reilly destaca que en el año 1960, la revista científica Nature publicó más de cincuenta artículos en relación con el ADN y, sin embargo, la estructura de la doble hélice estaba citada solamente en dos de ellos ${ }^{12}$.

${ }^{7}$ Hauser, 2005. Kac, 2007. Mitchell, 2010.

${ }^{8}$ Rifkin, 1998.

${ }^{9}$ Reichle, 2009: 17.

${ }^{10}$ Rubio Mayoral, 2006:15. Las palabras de Erwin Schrödinger fueron las siguientes: “¿Cómo pueden la Física y la Química dar cuenta de los fenómenos espacio-temporales que tienen lugar dentro de los límites espaciales de un organismo vivo?".

${ }^{11}$ Watson/Crick, 1953:737-738.

${ }^{12}$ Reilly, 2004: xii. 
En el contexto artístico, pocos años después de que Watson y Crick describieran la estructura molecular del ADN, Salvador Dalí realizó su obra Paisaje con mariposa. El Gran Masturbador en paisaje surrealista con ADN (1957-58), en la que incorporaba el ADN como elemento iconográfico de su composición. A esta obra le seguirían otras, que serán analizadas con posterioridad.

\section{Dalí y las ciencias}

El conocimiento científico de Dalí, que es más amplio y anterior a su interés por el ADN, abarcó múltiples disciplinas, desde el psicoanálisis hasta las matemáticas, la teoría de la relatividad, la física cuántica y la biología molecular. Si bien es cierto que en alguna ocasión Dalí negó, para sorpresa de muchos, esa influencia en alguna de las obras que precisamente se consideraban más influidas por la ciencia, como es el caso de la relación entre los relojes blandos de La persistencia de la memoria (1931) y la Teoría de la Relatividad de Einstein ${ }^{13}$, lo cierto es que las referencias a las contribuciones científicas son constantes en su obra. Ello es especialmente notable a partir del lanzamiento de las bombas atómicas al final de la II Guerra Mundial, cuando se desarrolla el interés por el átomo en obras tales como Idilio atómico (1945) o Leda atómica (1949), que también abarcará la antimateria (Galatea de las esferas, 1952) y, posteriormente, a las investigaciones sobre la cuarta dimensión a través de la figura del hipercubo (Crucifixión, también conocida como Corpus Hipercubus, 1954).

La demostración de que el interés científico de Dalí excede lo anecdótico es que no solo incorporó iconográficamente estos elementos en su obra sino que conoció y mantuvo relación con numerosos científicos, organizando encuentros y manteniendo correspondencia con ellos, interesándose por sus descubrimientos a través de conversaciones con los mismos e, incluso, suscribiéndose a publicaciones científicas tales como Science et Vie, Science and Invention o The Scientific American $^{14}$. De hecho, como apunta Carme Ruiz, la biblioteca del pintor contaba con más de un centenar de libros y revistas científicas ${ }^{15}$. Uno de los ejemplos más emblemáticos de la relación entre el pintor y la ciencia lo constituye el congreso titulado Proceso al azar, organizado con científicos en el Teatre-Museu Dalí de Figueras, en 1985, cuando Dalí estaba muy débil de salud, en el que se debatió sobre el papel del azar y la incertidumbre en la física, la biología y la historia. En ese congreso se dieron cita científicos de prestigio internacional, muchos de ellos premios Nobel, como el matemático René Thom (especialista en teoría de las catástrofes), Ilya Prigogine (Premio Nobel de Química y experto en la teoría del caos) o el catalán Ramon Margalef (especialista en ecología). El contenido de este congreso se publicaría un año después ${ }^{16}$. La ciencia, para Dalí, compartía con el arte una idéntica naturaleza experimental así como una vocación de conocer el mundo. Esta fue la idea principal de la intervención que dirigió a los asistentes al congreso de Figueras, titulada "El Enigma Estético": "Amics, mediteu i tingueu en compte el gran honor que ens fan els savis i els científics portant-nos aquí, sota la Cúpula del Museu, els seus coneixements. (...) El fenomen estètic va estretament lligat a la Història de la ciència encara que solament fóra pel simple fet que en tots dos es dóna l'elecció experimental" "'. La precisión con la que Dalí incorporaba las aportaciones de los científicos (como el hipercubo o la estructura del ADN, por citar

${ }^{13}$ Úbeda/Marquès/Pons, 2004. Ilya Prigogine, Premio Nobel de física, le preguntó, en el marco del encuentro celebrado en el Teatre-Museu de Figueres sobre esta relación, que el pintor desmintió, aduciendo que se había inspirado en un trozo de queso Camembert fundiéndose al sol.

${ }^{14}$ Giralt-Miracle, 2005:473.

15 Ruiz, 2010: 4.

${ }^{16}$ Wagensberg, 1986.

17 Wagensberg, 1986: 25. 
dos de los más precisos) demuestra en parte que su acercamiento a la ciencia podía ser heterodoxo pero no ignorante. Por otro lado, han quedado documentadas numerosas intervenciones de científicos que conocieron a Salvador Dalí que contribuyen a reconstruir la estrecha relación que mantenía el pintor con la ciencia ${ }^{18}$.

El historiador del arte Gavin Parkinson sostiene que la relación entre Dalí y la ciencia, refiriéndose especialmente a la física, responde también a razones artísticas. En este sentido, relaciona la génesis del surrealismo con una tendencia que no necesariamente procede de la línea iniciada por el romanticismo y continuada por el simbolismo, sino con la importancia que adquieren en Francia, y especialmente en París, a partir de 1919, las teorías de la física planteadas por Albert Einstein, cuando empiezan a demostrarse algunos de sus postulados ${ }^{19}$. En 1921, con motivo de la primera exposición de Max Ernst en la ciudad, André Breton teoriza algunos de los fundamentos teóricos que serán característicos del surrealismo, y lo hará, precisamente, estableciendo analogías con la física de Einstein. En palabras de André Breton: "La croyance en un temps et un espace absolus semble prête à disparaître. Dada ne se donne pass pour moderne. Il juge inutile, aussi, de se soumettre aux lois d'une perspective donnée... Mais la faculté merveilleuse, sans sortir du champ de notre expérience, d'atteindre deux réalités distantes et de leur rapprochement de tirer une étincelle; de mettre a la portée de nos sens des figures abstraites appelées a la même intensité, au même relief que les autres; et, en nous privant de système de réferénce, de nous dépayser en notre propre souvenir, voila qui provisoirement le retient" ${ }^{\prime 2}$. La teoría de la relatividad ofrecía una nueva manera de conceptualizar el espacio-tiempo, que se podía extrapolar al planteamiento de una nueva epistemología y también, como en el caso de Breton, a una nueva poética. Es lógico pensar que los descubrimientos de la física, que estaban alterando la misma definición del mundo, podían ser del gusto del surrealismo y del mismo Dalí, que conservaba en su biblioteca escritos de estos físicos. La nueva física dibujaba un mundo que cuestionaba la estabilidad de la física clásica, lo que puede ejemplificarse no solo con Einstein, sino con otros físicos también influyentes como son Erwin Schrödinger (1887-1961), y su famoso experimento mental del gato, y Werner Heisenberg (1901-1976), y su célebre principio de incertidumbre. De Heisenberg, diría Dalí lo siguiente, en el marco de su Manifiesto de la Antimateria de 1958: "Durante el periodo surrealista, he deseado crear la iconografía del mundo interior, el mundo de lo maravilloso, de mi padre Freud: lo he conseguido. Actualmente, el mundo exterior -el de la física- ha trascendido al de la psicología. Mi padre, hoy, es el doctor Heisenberg"21.

Partiendo de este marco de análisis general, y destacando que la relación entre Dalí y la física es una de las más estudiadas, puede afirmarse que no se ha desarrollado un análisis profundo de su relación con la biología. Es muy probable que la temprana referencia al ADN que hace Dalí en su obra Paisaje con mariposa. El Gran Masturbador en paisaje surrealista con ADN (1957-58) tenga que ver con la nueva alianza que se produce entre la ciencia de la biología y la ciencia física, que cristaliza en la biología molecular, teniendo en cuenta el interés que tenía la física para el pintor ampurdanés, especialmente desde el fin de la II Guerra Mundial. La aproximación de Dalí a la biología molecular es, en determinados aspectos, análoga a la establecida con otras ciencias, por lo que respecta a la asociación entre arte, ciencia y misticismo: la ciencia como un modo de acceder y desvelar los misterios de la Creación. En el caso particular de la biología molecular, sin embargo, existen evidencias de la asociación que estableció Dalí entre el ADN y la inmortalidad, especialmente en su texto "La inmortalidad del imperialismo genético" ${ }^{22}$. Pocos años antes de que se produjera este interés por la

\footnotetext{
${ }^{18}$ Úbeda/Marquès/Pons, 2004. Wagensberg, 2005.

${ }^{19}$ Parkinson, 2005: 101-119.

${ }^{20}$ Breton, 1988: 245-246.

${ }^{21}$ Giralt-Miracle, 2005: 471.

${ }^{22}$ Dalí, 2006: 833.
} 
biología, el artista había relacionado la física cuántica con el misticismo, en su Manifeste Mystique de $1951^{23}$. En una entrevista realizada a James D. Watson ${ }^{24}$, éste recordaba su primer encuentro con Salvador Dalí. El científico explica que constató el interés de Dalí por el ADN cuando contempló su obra Galacidalacidesoxirribonucleic (Hommage à Crick et Watson) en Boston. En 1965, Watson entró al Hotel St. Regis de Nueva York, donde se alojaba Dalí, y le escribió una nota: "El segundo hombre más brillante del mundo desea conocer al más brillante". Dalí bajaría inmediatamente a conocer al científico y concertaría una cita para encontrarse con él. Watson recuerda que Dalí le comentó con entusiasmo que el ADN demostraba la existencia de Dios ${ }^{25}$.

\section{Dalí y la biología molecular: catálogo de obras}

A continuación realizamos un análisis cronológico de las obras que Salvador Dalí dedicó a la biología molecular.

La primera obra que dedica Dalí al ADN es la mencionada Paisaje con mariposa. El Gran Masturbador en paisaje surrealista con ADN (1957-1958, fig. 1). La estructura en hélice del ADN, que había sido descrita por Watson y Crick, cuenta con un claro protagonismo en la composición, situado en el primer plano de un paisaje de horizonte infinito, característico del pintor. La iconografía del Gran Masturbador, que remite a la obra del mismo nombre realizada en 1929, se ha interpretado a menudo como un autorretrato de Dalí, por lo que su presencia en esta obra podría aludir a la singularidad asociada a la particular secuencia de ADN que caracteriza a todo ser vivo (incluido, naturalmente, los humanos), pudiéndose plantear el lienzo como un autorretrato doble: surrealista y genético. Esta interpretación cobraría también sentido a la luz de la gran cantidad de retratos y autorretratos que elaborarán los artistas asociados al "bioarte" en la década de los noventa, asociando cuestiones de identidad a la genética, en ejemplos como los de Steve Miller, en Genetic Portrait of Isabel Goldsmith (1993), Iñigo Manglano-Ovalle en sus distintas versiones de The Garden of Delights (1998) o Gary Schneider en Genetic Self-Portrait (1997-98). Retomando la obra de Dalí, la presencia de mariposas de distintos tamaños desempeña también un papel fundamental en el lienzo ya que éstas actúan de nexo entre la estructura del ADN y el resto de elementos de la composición, posándose en algunos casos en el ADN, desgajando algunas moléculas, y desplazándose de forma clara hacia el Gran Masturbador, en una posible alusión al ARN entendido como mensajero, que Dalí recuperará -como comentaremos más adelante- en obras posteriores como La escalera de Jacob (1975).

La siguiente obra que Dalí dedica al ADN es Galacidalacidesoxyribonucleicacid. Hommage à Crick et Watson (1963) (fig. 2) que conserva, junto con un estudio de la misma (fig. 3), la Fundación Gala-Salvador Dalí. Si bien las dos composiciones difieren en aspectos sustanciales, desde la iconografía al formato, es importante destacar, en primer lugar, el protagonismo de la figura femenina en ambas que, en la versión definitiva, aparecerá claramente retratada como Gala, que no solo es observadora de la escena, sino articuladora de la misma, origen o final de lo que ante ella sucede. La relación entre esta figura y el plano celeste es fundamental y se realiza mediante una "imagen doble" que encubre y revela la presencia de un cuerpo más o menos difuso -tanto como las nubes- del que surge un brazo que se posa sobre la cabeza de la figura femenina. El vínculo entre Gala y lo celestial debe vincularse a la naturaleza divina que Dalí asocia al ácido desoxirribonucleico, tal y como afirmó

\footnotetext{
${ }^{23}$ En este manifiesto, publicado originalmente en 1951, Dalí afirma lo siguiente: "la crisis paroxística del misticismo daliniano se apoya básicamente en el progreso de las ciencias particulares de nuestra época, especialmente en la espiritualidad metafísica de la substancialidad de la física cuántica” (Dalí, 2006: 636)

${ }^{24}$ Úbeda/Marquès/Pons, 2004.

${ }^{25}$ Íbid.
} 


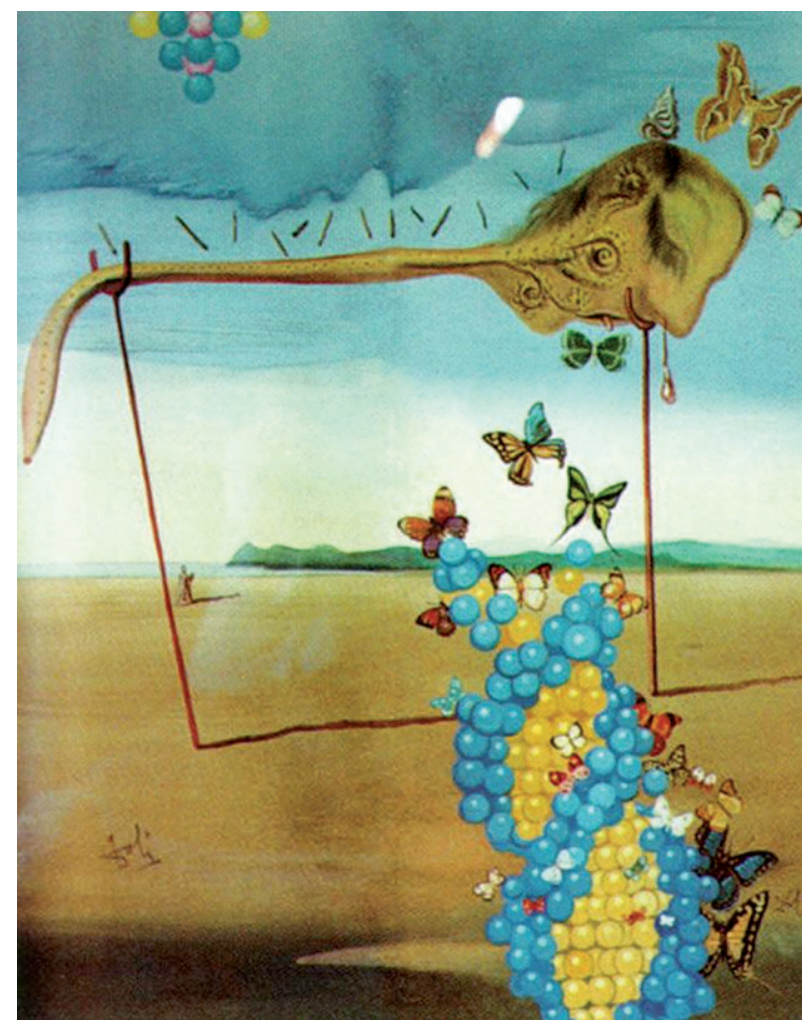

Fig. 1. Paisaje con mariposa. El Gran Masturbador en paisaje surrealista con ADN (1957-58). en una entrevista James D. Watson: en ella, el Nobel y codescubridor de la estructura molecular del ADN, explicó que Dalí le transmitió su entusiasmo por su descubrimiento ya que demostraba la existencia de Dios $^{26}$. Posteriormente, en 1973, Dalí reformuló esta relación entre ADN y la divinidad: "Los últimos descubrimientos de la genética nos demuestran que las leyes de Dios son las de la herencia contenidas en el ácido desoxirribonucleico" $^{27}$.

La asociación entre Gala, la divinidad y el ADN se ve reforzada si atendemos al contenido del filacterio que sostiene la figura del Creador, donde aparece el título de la obra "Galacidalacidesoxyrribonucleicacid", que constituye una síntesis entre la identidad de Gala y el ácido desoxirribonucleico. En el estudio de la obra, la contención en la cantidad de elementos, permite apreciar con claridad que existen tres elementos básicos que para Dalí eran importantes desde un inicio: la figura femenina, la figura masculina que hace descender su brazo hasta ella (ambas aludidas anteriormente) y un tercer elemento, las nubes, de las que es importante destacar su composición en

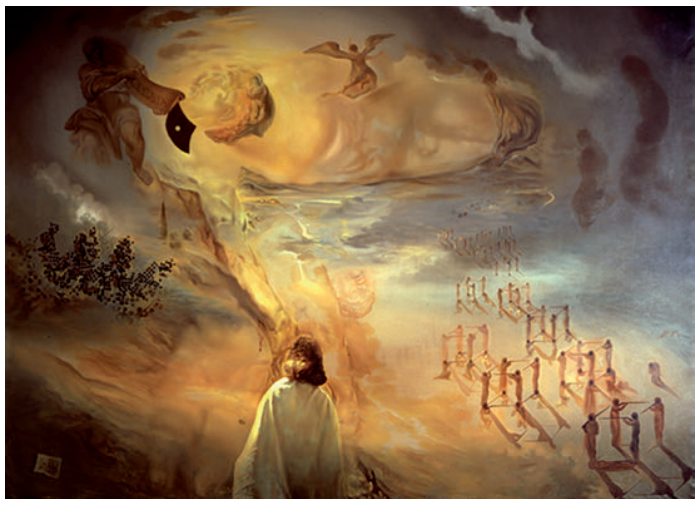

Fig. 2. Galacidalacidesoxyribonucleicacid. Hommage à Crick et Watson (1963).

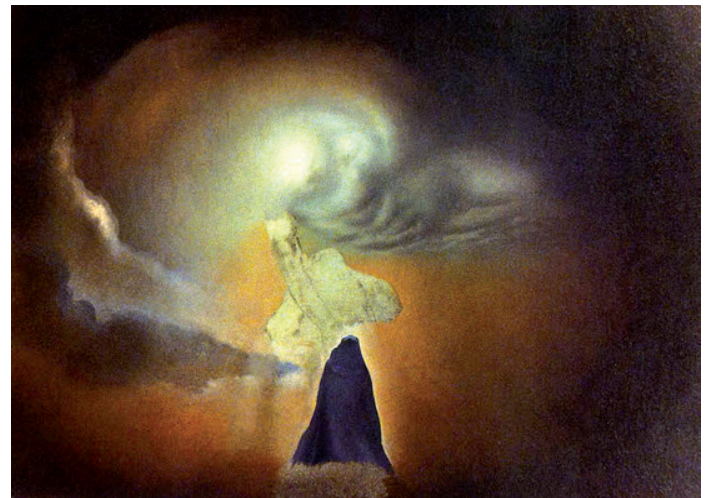

Fig. 3. Estudio para Galacidalacidesoxyribonucleicacid. Hommage à Crick et Watson (1963).

\footnotetext{
${ }^{26}$ Úbeda/Marquès/Pons, 2004.

${ }^{27}$ Dalí, 2006: 833.
} 


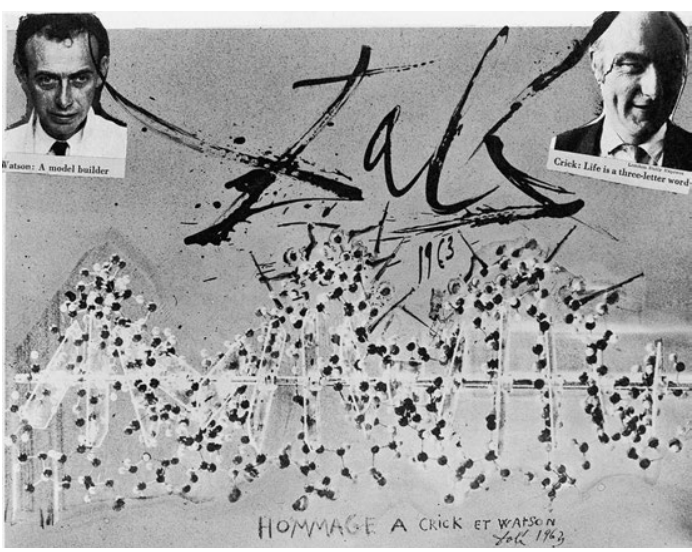

Fig. 4. Homenaje a Crick y Watson, 1963.

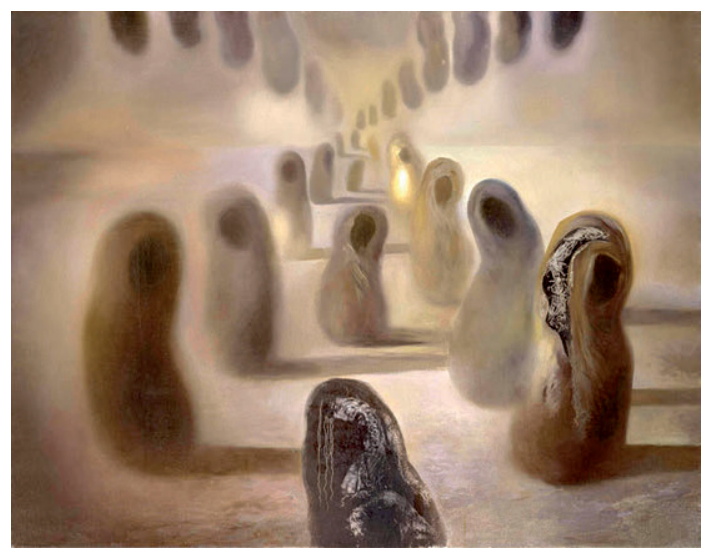

Fig. 5. Árabes acidodesoxirribonucleicos, 1963.

espiral (no tan clara en la versión definitiva), de la que no puede dejar de señalarse su analogía formal con la estructura molecular del ADN descrita por Watson y Crick. Esta estructura reaparecerá y obras sucesivas de Dalí e irá adquiriendo nuevas connotaciones simbólicas.

La recurrencia a esta estructura en la obra de Dalí debe entenderse, desde nuestro punto de vista, en el marco de la asociación que el pintor establecía entre la geometría y la divinidad, entendiendo precisamente que las formas geométricas presentes en la naturaleza son el producto de la voluntad divina: "Aunque yo no soy científico, debo confesar que los acontecimientos [científicos] son los únicos que guían constantemente mi imaginación, al mismo tiempo que ilustran la intuición poética de los filósofos tradicionales, hasta el punto de llegar a la belleza cegadora de ciertas estructuras matemáticas, especialmente las de los politopos y sobre todo esos sublimes momentos de abstracción que «vistos» a través del microscopio electrónico aparecen como virus de forma poliédrica regular, confirmando lo que dijo Platón: Dios siempre hace geometría. ${ }^{28}$ Es desde este prisma desde el que deben analizarse las estructuras moleculares que aparecen en la parte inferior derecha de la composición definitiva de Galacidalacidesoxyrribonucleicacid, encarnadas en una serie de figuras humanas que, unidas por bastones, componen formas cúbicas perfectamente regulares, que van alejándose hacia el horizonte.

En el mismo 1963 Dalí realiza el collage titulado Homenaje a Crick y Watson (fig. 4), que serviría como imagen de la cubierta del catálogo en homenaje a los descubridores del ADN. La composición destaca por la presencia de dos retratos fotográficos de los científicos, situados a ambos lados de una gran firma de Dalí. En la parte inferior se sitúa una imagen de la estructura molecular del ADN, sobre la que hay dibujadas pequeñas figuras humanas que, con bastones, parecen trabajar en la composición o descomposición de la estructura, desempeñando la función del ARN. En este sentido, la presencia de figuras humanas como articuladoras de la estructura, remite al ARN, un motivo que ya estaba presente en Galacidalacidesoxyrribonucleicacid y que se repetirá en La escalera de Jacob, que se analizará más adelante.

Una última obra, del mismo año 1963, que es importante para el tema que nos ocupa a pesar de que su referencia no es frecuente es Árabes acidodesoxirribonucleicos (fig. 5), para la que el pintor realizó al menos una composición preparatoria. Se trata de unas composiciones fundamentales para asentar la importancia de la estructura molecular que en las obras que Dalí asocia al

${ }^{28}$ Rubio Mayoral, 2006: 93-132. 


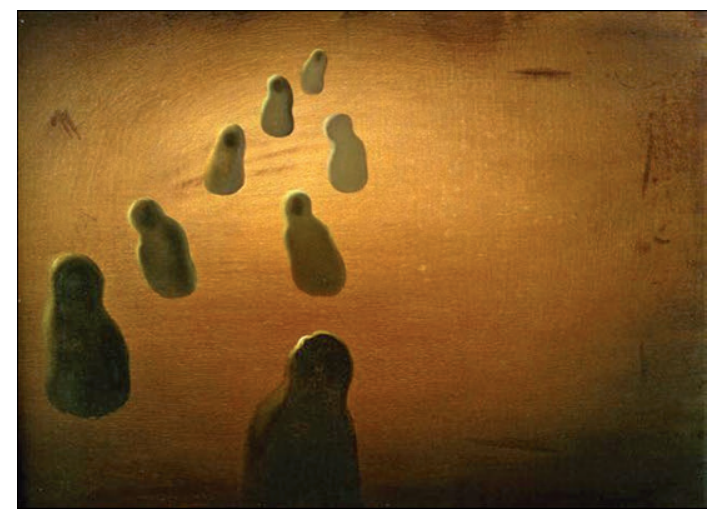

Fig. 6. Estudio para Árabes acidodesoxirribonucleicos, 1963.

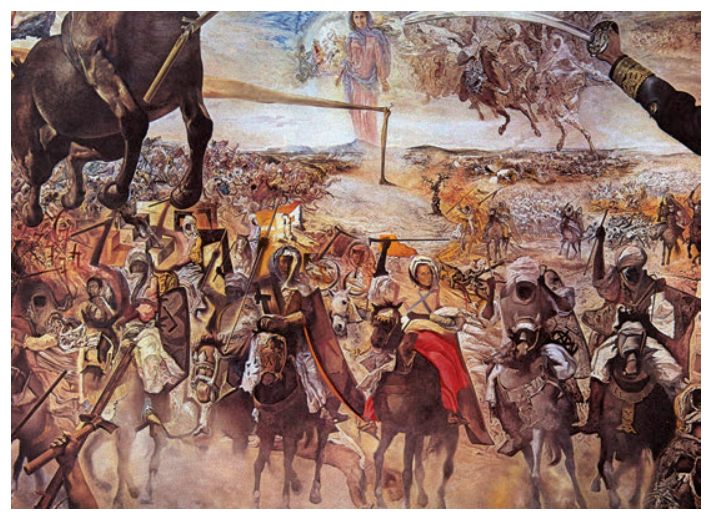

Fig. 7. La batalla de Tetuán (Homenaje a Mariano Fortuny), 1961-62.

ADN, pero también para completar el valor simbólico que se les asocia que, como veremos, establece relaciones con otras obras, que no se asociarían directamente al ADN, como es el caso de La batalla de Tetuán (Homenaje a Mariano Fortuny), realizada poco antes (1961-62) de las obras que estamos analizando.

En la composición preparatoria de Árabes desoxirribonucleicos (fig. 6), Dalí sitúa dos filas de formas redondeadas situadas en una composición fugada. En su versión definitiva, el fondo de la composición está, a diferencia del estudio, ligeramente definido por medio de la línea del horizonte, y las formas redondeadas son más numerosas, formando cuatro hileras principales que, al alejarse hacia el horizonte acusan una ligera torsión, que las acerca a la estructura helicoidal del ADN, lo que quedaría confirmado por la alusión al ADN en el título de la obra. Sin embargo, al poner en relación esta pintura con su obra La batalla de Tetuán (Homenaje a Mariano Fortuny) (1961-62) (fig. 7), un homenaje a la pintura de historia realizada, con el mismo título, por el pintor Mariano Fortuny entre 1862 y 1864, encontramos sintonías formales, como la representación de los personajes con turbante blanco y con el rostro indefinido en negro, que particularizan esas "formas redondeadas" a las que aludíamos más arriba. La iconografía de estos árabes, que están representados a caballo en La batalla de Tetuán daliniana, contribuye a identificar las figuras que aparecen a la izquierda de la composición de Galacidalacidesoxyribonucleicacid, donde se representan diversos jinetes a la izquierda de la composición. Este aspecto se ve reforzado por la existencia de un estudio de La batalla de Tetuán de Dalí (fig. 8), exclusivamente centrado en un grupo de jinetes que avanzan hacia el espectador, quedando su identidad completamente indefinida por la ausencia de rasgos en el rostro. Existe un texto que Dalí dedicó a La batalla de Tetuán que permite dilucidar la asociación entre la estructura helicoidal y el mundo árabe que se encuentra en Árabes acidodesoxirribonucleicos: "Dalí, fascinado por la biología moderna, considera que la persistencia de la memoria se encuentra localizada en el ADN, cuyas dos espirales son el mundo cristiano y el mundo musulmán entrelazados, y la historia tan solo es la persistencia genética de las dos memorias" ${ }^{\prime 2}$. La característica doble hélice del ADN (que estaría duplicada en la versión definitiva de la obra) tiene, por tanto, un doble sentido para Dalí: temporal, al relacionarse con la conservación (la persistencia) de la memoria, lo que se ve reforzado por el hecho de que La Batalla de Tetuán pertenece al género de la Pintura de Historia; y, en relación con lo anterior, cultural, al simbolizar en entrelazamiento de las culturas cristiana y musulmana.

${ }^{29}$ Dalí, 2006: 743. 


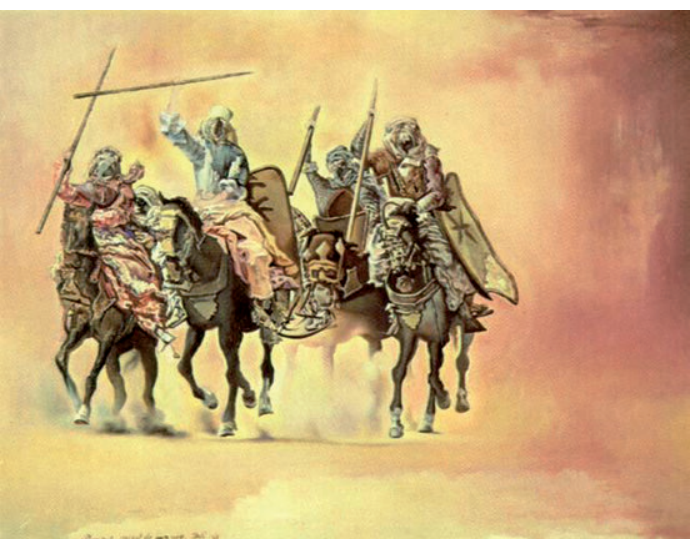

Fig. 8. Estudio para La batalla de Tetuán (Homenaje a Mariano Fortuny), 1961.

Fig. 9. Cubierta de la publicación en homenaje a Severo Ochoa donde se reproduce la composición de Dalí La escalera de Jacob, 1975.

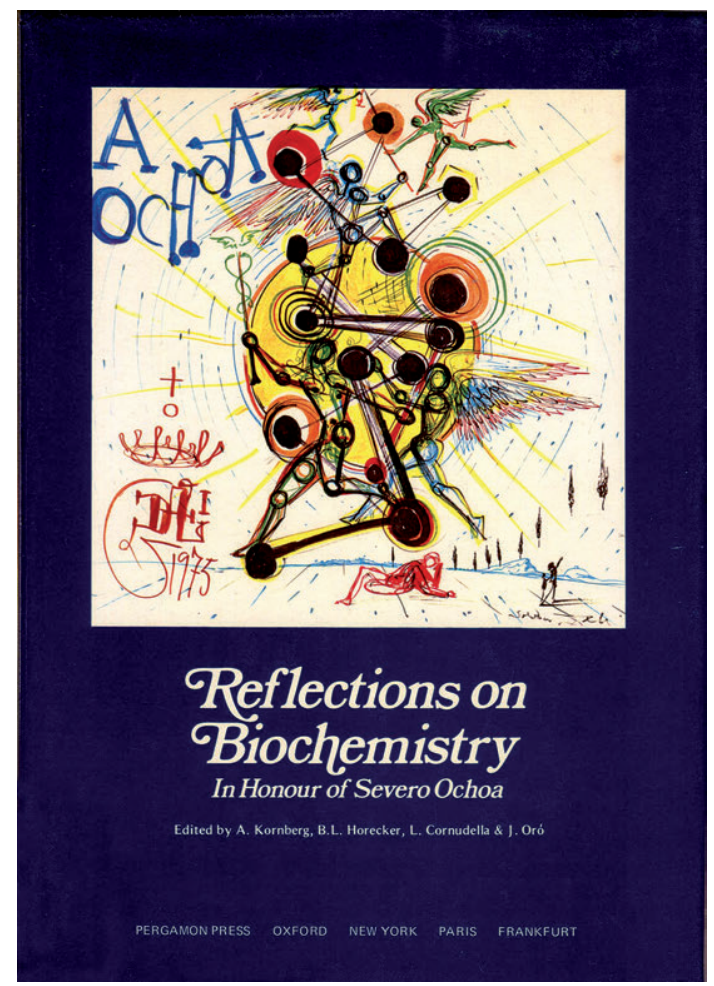

La siguiente obra en la que Dalí alude al ADN tiene relación con el Premio Nobel Severo Ochoa (1905-1993). En 1975, en un homenaje al científico con motivo de su septuagésimo aniversario, se organizó un simposio internacional para el que se encargó a Dalí un dibujo, La escalera de Jacob, que después aparecería en la cubierta del libro que se derivó del encuentro (fig. 9) ${ }^{30}$. El dibujo representa una estructura sobre la que ascienden ángeles. El mismo Severo Ochoa explicó que la obra trazaba un paralelismo entre la biología molecular y la historia bíblica ya que se representaba el ADN como la escalera que había visto Jacob en sueños y que utilizaban los ángeles (que simbolizan el ARN) para ascender y descender de los cielos ${ }^{31}$. También Dalí explicó esta asociación en su texto "La inmortalidad del imperialismo genético": "el ácido desoxirribonucleico, ARN, no es más que el mensajero encargado de transmitir el código genético (...) formando así la escala de Jacob de Crick y Watson. En la escala de Jacob cada escalón es un rellano ADN y los ángeles que suben y bajan son el ARN" ${ }^{\prime 32}$. Por este motivo la obra ha recibido el título de El ácido desoxirribonucleico y la escalera de Jacob o, sencillamente, La escalera de Jacob. En esta obra, el vínculo entre genética y religiosidad es claro, y el ADN actúa como conector entre lo divino y lo humano. Por otro lado, Dalí incorpora una alusión clara al ARN, haciendo alusión al dogma central de la biología molecular, que, como habíamos mencionado, teorizó Francis Crick en 1958, tal y como confirmó en una entrevista posterior: "Por ejemplo, por lo que respecta al cáncer, yo me basaba, sobre todo, en lo que sabía de los mensajeros, de los que llevan paquetes, los repartidores. El mensajero, en

\footnotetext{
${ }^{30}$ Kornberg, 1976.

${ }^{31}$ Ochoa, 1983, 71-72.

32 Dalí, 2006: 833.
} 
biología, es el ARN, el ácido ribonucleico"33. Es en este sentido en el que proponíamos que la función que desempeñaban las mariposas de la obra Paisaje con mariposa (1957-58), o las figuras humanas en el Homenaje a Watson y Crick (1963), era la de ese "ARN mensajero". El mismo Dalí acompañó con un texto esta obra realizada en homenaje al científico español, que confirma lo dicho hasta ahora: "Dios no juega a los dados, escribió Albert Einstein mucho antes de la escalera del $\mathrm{ADN}$, cuyos peldaños recorren los ángeles en el sueño de Jacob que yo tuve la noche antes de dibujar esto para Severo Ochoa; estos ángeles simbolizan los mensajeros del código genético, o las moléculas de polinucleótidos sintetizadas por primera vez en el laboratorio de Severo Ochoa" ${ }^{34}$. Dalí enfatiza, en esta cita la asociación entre la estructura del ADN y la divinidad, aportando nuevos valores a la importancia que hemos visto que tienen las recurrentes estructuras moleculares. En este sentido, no solo deben interpretarse como una presentación precisa y fiel al modelo científico del ADN sino también como la el símbolo de una estructura que, asociada al orden presente en el mundo, tiene su último origen en la divinidad.

Posteriormente, en La estructura del ADN (1975-1976), Dalí recupera la idea del orden geométrico al representar las estructuras moleculares compuestas por esferas y líneas que articulan el cuerpo de tres figuras antropomórficas que se encaraman una encima de la otra, colocadas en un paisaje desnudo. Lo más destacable de esta obra, además de la estructura de las figuras, es su presentación relacionada con los experimentos ópticos de Dalí. En este sentido, la obra está formada por dos composiciones yuxtapuestas, prácticamente idénticas, que se presentan con un doble espejo en el centro, produciendo en el espectador una sensación de volumen, si éste coloca su mirada en el centro. Esta obra aparece representada como un elemento más en otra obra del pintor, tal y como ha recogido Carme Ruiz ${ }^{35}$, El pie de Gala (c. 1975-76).

\section{El camino del enigma (1981): ¿una última obra dedicada al ADN?}

La obra anterior, La estructura del $A D N$, constituiría el último hito de la relación entre Dalí y la biología molecular, que abarcaría, por tanto, desde el año 1957 a 1976, aunque lo cierto es que la importancia de esta bien es cierto, como he hemos relación ha sido escasa, sobre todo si tenemos en cuenta que, muy frecuentemente, la única obra que la documentaba se reducía a Galacidalacidesoxyrrinocleicacid. Hommage à Watson et Crick.

Consideramos que en este catálogo podría incluirse la obra El camino del enigma (fig. 10) realizada en 1981, que quizá haya pasado desapercibida en cuanto al interés de Dalí por la biología molecular porque en su título no se explicita claramente esta relación. Aunque el pintor había aludido en otras ocasiones al concepto de "enigma", en obras como El enigma del deseo (1929), El enigma de Hitler (1937) o El enigma sin fin (1938), lo cierto es que El camino del enigma no guarda un parecido formal ni conceptual con las obras mencionadas, como sí por ejemplo con la composición de La carne de gallina inaugural (1928), por las formas redondeadas que la componen y por su composición fugada. Sin embargo, pueden aducirse algunas razones para justificar el establecimiento de analogías entre las obras que Dalí dedica a la biología molecular de una forma explícita y El camino del enigma, tanto desde un punto de vista formal como conceptual.

Desde un punto de vista formal, tres de las citadas composiciones de 1963, Galacidalacidesoxyribonucleicacid y Árabes acidodesoxirribonucleicos (tanto en su composición preparatoria como en su versión definitiva), utilizan la composición fugada para la representación del ADN, a

\footnotetext{
${ }^{33}$ Fogel/Hue, 1976.

${ }^{34}$ Rubio Mayoral, 2006: 93-132.

${ }^{35}$ Ruiz, 2010: 12.
} 


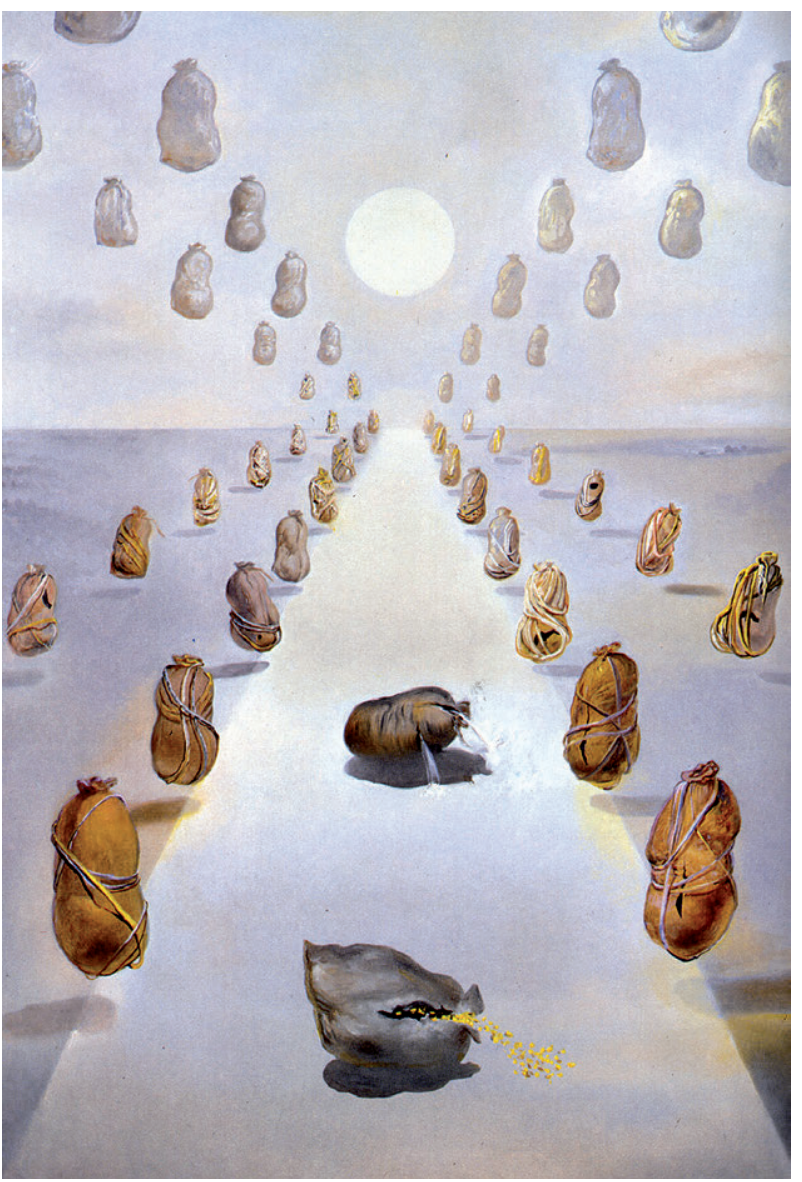

Fig. 10. El camino del enigma, 1981.

la que podría sumarse una cuarta, el Estudio para Galacidalacidesoxyribonucleicacid, si aceptáramos que la composición helicoidal de las nubes remite a la estructura del ADN. En cualquier caso, el pintor aprovecha sus lejanos horizontes para articular las estructuras en perspectiva, conectando lo más próximo y lo más lejano en una solución de continuidad. En otros casos esta conexión no se establece en profundidad sino mediante un eje vertical, que aludiría a la comunicación entre lo divino y lo humano, como en el caso de La escalera de Jacob, conceptualizando el ADN como algo universal y divino. La composición fugada se mantiene en El camino del enigma, a pesar de que la morfología de las figuras guarda una mayor sintonía con las formas de Árabes acidodesoxirribonucleicos, tanto en su estudio preparatorio como en su versión definitiva. En este último caso, el parecido con $E l$ camino del Enigma es notable, no solo por la composición fugada y por la morfología de las figuras sino especialmente por la presencia de cuatro ejes, que en el caso de la obra de 1981 son dobles, pero conservando esa misma estructura.

Desde un punto de vista conceptual, la relación no es, en apariencia, tan clara, para empezar porque el título no hace una referencia directa al $\mathrm{ADN}$, sino o al "enigma": se trata de dos conceptos que, como trataremos de ilustrar, podrían pertenecer a un mismo campo semántico, hasta el punto de compartir referente: la estructura molecular del ácido desoxirribonucleico. La explícita referencia al "enigma" se adecua a la iconografía utilizada, compuesta por sacos perfectamente cerrados (ocultando su interior) con cuerdas, aunque dos de ellos, precisamente los que se encuentran intercalados en el centro (de una forma análoga a la versión definitiva de Árabes acidodesoxirribonucleicos), parecen haberse roto, descubriendo su interior.

El concepto de "enigma" ha sido uno de los conceptos más ligados al ADN, entendido como molécula primigenia de la vida (en la que Dalí sitúa su divinidad) pero también como secreto que descifrar. El mismo James D. Watson tituló sus memorias DNA. The Secret of Life ${ }^{36}$ y escribió que con la descripción de la estructura molecular del ADN en 1953 no se terminaba un proceso sino todo lo contrario: se abría un largo camino consistente en el "desciframiento" del mismo, refiriéndose a la necesidad de localizar el "botín genético" e interpretando el código genético como la "Piedra Roseta de la Vida". Para el Nobel, el descubrimiento de la estructura molecular del ADN constituía, a la luz del título de la obra de Dalí, el inicio del camino para descifrar el enigma de

\footnotetext{
${ }^{36}$ Watson, 2004.
} 
la vida. Esta será la motivación que guiará el Proyecto Genoma Humano, que se empezó a gestar en los años ochenta a pesar de que su inicio se producirá en 1990, con el objetivo de "decodificar el genoma humano", es decir, descifrar el orden de la particular secuencia del ADN humano.

La idea de desciframiento asociada al ADN entendido como "enigma" no se comprende del todo sin referirse a otro de los términos que empezará a cobrar fuerza a partir de los años cuarenta: la idea de "código genético" para referirse al ADN. Tal y como mencionábamos a propósito del texto What is Life?, publicado por Erwin Schrödinger en 1944, la biología molecular permitió conceptualizar el genoma como información, como código genético, entendiendo que existía una particular secuencia en la que la información genética se encriptaba y que, de algún modo, podía ser descifrada. En los años cuarenta, de hecho, se produce una filtración entre conceptos procedentes de la teoría de la información y los procesos biológicos, lo que propició la formación de metáforas tales como "código genético" o "información genética", que entroncan con la potente metáfora del "Libro de la Vida", estudiada por Lily E. Kay. ${ }^{37}$

En 1958, el que sería Premio Nobel Max Delbrück, envió un mensaje codificado a George W. Beadle, poco después de que éste obtuviera el Premio Nobel por sus descubrimientos relacionados con la genética. El mensaje era, estrictamente, una estructura compuesta por diversos palillos de colores, que codificaba una frase utilizando, en lugar de las bases que componen el genoma (AC-T-G: Adenina, Citosina, Timina, Guanina), cuatro colores distintos. Delbrück se basó en la idea del genoma entendido como código, para traducir una frase en inglés a la lógica del código genético. La secuencia de estos cuatro colores encriptaba la siguiente frase: "I am the riddle of life [el secreto de la vida] know me and you will know yourself" 38 , que Beadle tuvo que descifrar. La idea del secreto, como la del desciframiento, está en el imaginario asociado al ADN. No olvidemos, por último, que el mismo Dalí decidió encabezar su presentación al congreso celebrado en 1985 en el Teatre-Museu de Figueras con el título "El enigma Estético". La palabra "enigma", en definitiva, estaba asociada a la conceptualización del ADN, por lo que resultaría especialmente adecuado que Dalí la utilizara para una de las obras dedicadas al ADN, especialmente en una que guarda estrechas similitudes formales y compositivas con las otras obras que dedicó al tema.

En su conjunto, la obra analizada de Dalí constituye el primer ejemplo que relaciona la biología molecular y el arte destacando, una última vez, la importancia de avanzar el interés de Dalí por la biología molecular hasta el año 1957, cuando dedica su primera obra al tema, revelando la temprana atención del artista a este ámbito científico. Como se ha podido apreciar, el pintor incorpora el repertorio científico relacionado con el ADN (y, muy especialmente, su estructura molecular en hélice) como parte de su imaginario artístico, lo que se traduce en la conformación de una verdadera iconografía del ADN en clave daliniana. En este sentido, es conveniente destacar que la relación que establece Dalí con la biología molecular, centrado especialmente en el ADN, no se corresponde con un interés puntual sino que responde a un proceso de años durante los cuales se conforman los valores, estructurales y simbólicos, que conforman una verdadera poética daliniana de la biología molecular.

Imágenes: C Salvador Dalí, Fundación Gala-Salvador Dalí, VEGAP, Barcelona, 2015.

\footnotetext{
${ }^{37}$ Kay, 2000.

${ }^{38}$ Reichle, 2009: 108. La cursiva es mía.
} 


\section{BIBLIOGRAFÍA}

Breton, André (1988): Oeuvres completes (Vol. I). Paris: Gallimard.

Dalí, Salvador (2006): Obra completa (Vol. 4). Barcelona: Destino.

Fogel, Jean-François/Hue, Jean-Louis (1976): “Un inédit du Sauvage: Les Mandales de Dalí”. En: Le Sauvage, 34, s/p. En : < http://www.lesauvage.org/2013/01/un-inedit-du-sauvage-les-mandalas-de-dali/> [26/01/2015]

Giralt-Miracle, Daniel (2005): "La curiositat científica de Salvador Dalí". En: Memorias de la Real Academia de Ciencias y Artes de Barcelona ("Dalí y la ciència. Homenatge de la Reial Acadèmica de ciències i Arts de Barcelona a salvador Dalí”), LXI, 10, pp. 474-475.

Hauser, Jens (2005): "Bio Art-Taxonomy of an Etymological Monster". En: Schöpf, Christine/Stocker, Gerfried (eds.) (2005): Ars Electronica 2005 Hybrid - living in paradox. Wien: Ars Electronica, s/p.

Kac, Eduardo (ed.) (2007): Signs of Life. Bio Art and Beyond. London/Cambridge: MIT Press.

Kay, Lily E (2000): Who Wrote the Book of Life? A history of the Genetic Code. Stanford: Stanford University Press. Kornberg, Arthur (ed.) (1976): Reflections on Biochemistry. In honour of Severo Ochoa. Oxford: Pergamon Press.

López del Rincón, Daniel/Cirlot, Lourdes (2013): "Historiando el bioarte o los retos metodológicos de la historia del arte (de los medios)". En: Artnodes, 13, pp. 62-71.

López del Rincón, Daniel (2015): Bioarte. Arte y vida en la era de la biotecnología. Madrid: Akal.

Martin, Jean-Hubert (comis.) (2013): Dalí. Todas las sugestiones poéticas y todas las posibilidades plásticas. Madrid: Museo Nacional de Arte Reina Sofía/TF Editores.

Mitchell, Robert (2010): Bioart and the vitality of media. Seattle: Washington University Press.

Ochoa, Severo (1983): "La meva amistat amb Salvador Dalí". En: 400 Obres de 1914 a 1983. Salvador Dalí . Madrid: Generalitat de Catalunya / Ministerio de Cultura / Obra Cultural de la Caixa de Pensions, 71-72.

Parkinson, Gavin (2005): "De Max Ernst a Ernst Mach, o surrealisme, física moderna i epistemologia". En: Wagensberg, Jorge (ed.) (2005): Dali. Noves fronteres de la ciència, l'art i el pensament. Barcelona: KRTU/Generalitat de Catalunya, pp. 101-119.

Reichle, Ingeborg (2009): Art in the age of technoscience. Genetic engineering. Robotics, and Artificial Life in Contemporary Art. Wien/New York: Springer.

Reilly, Philip. R. (2004): "Divining DNA". En: Anker, Suzanne/Nelkin; Dorothy (2004). The Molecular Gaze. Art in the Genetic Age. New York: Cold Spring Harbor, pp. xi-xv.

Rifkin, Jeremy (1998): The Biotech Century. New York: Tarcher/Putnam.

Rubio Mayoral, Juan Luis (2006): "Posibilidades de la literatura en la educación. Narraciones científicas y seudocientíficas”. En: Gómez García, María Nieves/Flecha García, Consuelo/Corts Giner, María Isabel (eds.) (2006): La Literatura y la Educación: Perspectivas históricas. Educación en la Literatura y Literatura en la Educación. Sevilla: Fundación El Monte.

Ruiz, Carme (2010): "Salvador Dalí y la ciencia, más allá de una simple curiosidad. En: Pasaje a la ciencia, 13, pp. 4-13. Senent Josa, Joan (1988): “Arte, ciencia, Dalí”. En: Ajoblanco, 10.

Úbeda, Joan/Marquès, Susi/Pons, Eli/ López, Mònica (2004): Dimensión Dali [DVD]. Barcelona: Grupo Mediapro.

Wagensberg, Jorge (ed.) (1986): Procès a l'atzar. Barcelona: Tusquets.

Wagensberg, Jorge (ed.) (2005): Dalí. Noves fronteres de la ciència, l'art i el pensament. Barcelona: Generalitat de Catalunya.

Watson, James D. (2004): DNA. The Secret of Life. London: Arrow Books.

Watson, James D./Crick, Francis (1953): “A Structure for Deoxyribose Nucleic Acid”. En: Nature, 171, pp. 737-738.

Fecha de recepción: 30-I-2015

Fecha de aceptación:17-VI-2015 